\title{
Questes
}

\section{Violences médiévales : éléments bibliographiques}

\section{Léonard Dauphant}

\section{(2) OpenEdition}

\section{Journals}

\section{Édition électronique}

URL : http://journals.openedition.org/questes/433

DOI : 10.4000/questes.433

ISSN : 2109-9472

\section{Éditeur}

Les Amis de Questes

\section{Édition imprimée}

Date de publication : 15 mars 2008

Pagination : 102-104

ISSN : 2102-7188

\section{Référence électronique}

Léonard Dauphant, «Violences médiévales : éléments bibliographiques », Questes [En ligne], 14 | 2008, mis en ligne le 01 janvier 2014, consulté le 15 septembre 2020. URL : http://journals.openedition.org/ questes/433 


\title{
Pistes bibliographiques
}

\author{
COLLECTIF
}

\section{VOLUMES COLLECTIFS}

Domestic Violence in Medieval Texts, éd. Eve SAlisbury, Georgiana Donavin et Merall Llewelyn PRICE, Gainesville FL, University Press of Florida, 2002.

Fifteenth-Century Studies, 27, éd. Edelgard DuBRUCK et Yael Even, 2002.

Gewalt und ihre Legitimation im Mittelalter, Symposium des Philosophischen Seminars der Universität Hannover vom 26. bis 28. Februar 2002, éd. Günther Mensching, Eckhard Homann, Heiner LOHL et Michael StÄDTLER, Würzburg, Königshausen und Neumann, 2003.

La Guerre, la violence et les gens au Moyen Âge. Actes du $119^{e}$ Congrès national des sociétés historiques et scientifiques, 26-30 octobre 1994, Amiens, Section d'histoire médiévale et de philologie, éd. Philippe CONTAMINE et Olivier GuYOTJEANnIn, tome 1 : Guerre et violence, tome $2:$ La Violence et les gens, Paris, CTHS, 1996.

Histoire et criminalité de l'Antiquité au XX siècle, Nouvelles approches, Actes du colloque de Dijon-Chenove, 3-5 octobre 1991, éd. Benoît GARNOT, Dijon, Éditions Universitaires de Dijon, 1992.

Religion, pouvoir et violence du Moyen Âge à nos jours, Rencontres d'histoire religieuse de Sylvanès, éd. Michel BerTRAND et Patrick CABAnEl, Toulouse, Presses universitaires du Mirail, 2004.

Violence and Civil Discorder in Italian Cities, 1200-1500, Symposium Sponsored by the Center for Medieval and Renaissance Studies of the University of California, Los Angeles, May 1969, éd. Lauro MARTINES, Berkeley, California University Press, 1972.

La Violence dans le monde médiéval, Aix-en-Provence, Presses de l'Université de Provence (coll. Senefiance 36), 1994.

Violence et contestation au Moyen Âge. Actes du $114^{e}$ Congrès national des sociétés savantes, Section d'histoire médiévale et de philologie, Paris, Comité des travaux 
historiques et scientifique, 1989.

La Violence et la mer dans l'espace atlantique du XII au XIX siècle, Actes du colloque international tenu à la Rochelle et à Rochefort, 14-16 novembre 2004, éd. Mickaël Augeron et Mathias Tranchant, Rennes, Presses Universitaires de Rennes, 2004.

\section{LIVRES ET ARTICLES}

Aurell, Martin, et Thomas Deswarte, éd., Famille, violence et christianisation au Moyen Âge. Mélanges offerts à Michel Rouche, Paris, Presses de l'Université ParisSorbonne, 2005 (coll. Cultures et civilisations médiévales, 31).

BoONE, Marc, "Armes, coursses, assemblees et commocions 》: les Gens de métiers et l'usage de la violence dans la société urbaine flamande à la fin du Moyen Âge, Lille, Taillandier / Bruxelles, Van Oest / Villeneuve d'Asq, Revue du Nord, 2005.

DE COMBARIEU, Micheline, «Le goût de la violence dans l'épopée médiévale », Aixen-Provence, Publications de l'Université de Provence, 1976, p. 35-67 (coll. Senefiance, 1).

CORMIER, Raymond, "Brutality and Violence in Medieval French Romance and its Consequences », Violence in Medieval Courtly Literature, éd. Albrecht Classen, New York et London, Routledge, 2004, p. 67-82.

Gauvard, Claude, "De Grace especial », Crime, Etat et Société en France à la fin du Moyen Âge, Paris, Publications de la Sorbonne, 1991, 2 vol.

Violence et ordre public au Moyen Age, Paris, Picard, 2005 (coll. Les Médiévistes français, 5).

GONTHIER, Nicole, Le châtiment du crime au Moyen Âge (XII ${ }^{e}-X V I^{e}$ siècles), Rennes, Presses Universitaires de Rennes, 1998.

GuENÉE, Bernard, Un Meurtre, une société : l'assassinat du duc d'Orléans, 23 novembre 1407, Paris, Gallimard, 1992.

JACKSON, William H., "Court Literature and Violence in the High Middle Ages », dans The Camden House History of German Literature, vol. 3, Germam Literature of the High Middle Ages, Rochester NY, Camden House, 2006, p. 263-276.

MOREL, Barbara, Une Iconographie de la répression judiciaire, le châtiment dans les enluminures en France du treizième au quinzième siècle, Paris, Éditions du CTHS, 2007. 
Nirenberg, David, Communities of Violence. Persecution of Minorities in the Middle Ages, Princeton, Princeton University Press, 1996 (trad. fr. Violence et minorités au Moyen Âge, préf. Claude GAUVARD, Paris, PUF, 2001).

PAYEN, Jean Charles, «Une poétique du génocide joyeux: devoir de violence et plaisir de tuer dans la Chanson de Roland », Olifant, 6 (1979), p. 226-236.

RAYNAUD, Christiane, La violence au Moyen Âge, XIII ${ }^{e}-X V^{e}$ siècles d'après les livres d'histoire en français, éd. thèse avec préf. Michel PASTOUREAU, Paris, Le Léopard d'Or, 1990.

SzKILNIK, Michelle, "Courtoisie et violence : Alexandre dans le Cycle du Paon», Alexandre le Grand dans les littératures occidentales et proche-orientales. Actes du Colloque de Paris, 27-29 novembre 1999, éd. Laurence Harf-Lancner, Claire Kappler et François Suard, Nanterre, Centre des sciences de la littérature de l'Université de Paris X-Nanterre (Littérales. Hors série), 1999, p. 321-339.

Verbruggen, Jan Frans, The Art of Warfare in Western Europe during the Middle Ages from the Eighth Century to 1340, traduit du hollandais en anglais par Summer WILLIARD and S. C. M. SOUTHERN, Amsterdam, Richard Vaughan, 1977.

White, Stephen D., «Repenser la violence de 2000 à 1000 », Médiévales, 113 (1999), p. 99-114. 